\title{
A STUdY OF THE PHASE DECOMPOSITION OF Fe-Ni-Al-Mo ALLOYS
}

\author{
M.K. Miller*, M.G. Hetherington**, J.R. Weertman*** and H.A. Calderon*** \\ *Metals and Ceramics Division, Oak Ridge National Laboratory, Oak Ridge, TN 37831-6376. \\ **Department of Materials, University of Oxford, Oxford, OX1 3PH, Great Britain \\ ***Department of Materials Science and Engineering, Northwestern University, Evanston, Il \\ 60208 .
}

\section{ABSTRACT}

The aging of $\beta^{\prime} \mathrm{NiAl}$ precipitates in ferritic $\mathrm{Fe}-\mathrm{Ni}-\mathrm{Al}$ alloys has been studied by transmission electron microscopy (TEM) and atom-probe field-ion microscopy (APFIM). The addition of Mo alters the lattice parameter of the phases and segregation of Mo to the interface between the matrix and the particles may alter the interfacial energy. The compositions of the matrix, precipitates and interfaces have been measured by TEM and APFIM. The results are compared.

\section{INTRODUCTION}

Superalloys derive their mechanical stability at elevated temperatures from the presence of small ordered coherent precipitates. The Fe-Ni-Al-Mo system is being studied because a) it has potential as the base of an Fe-based superalloy, if stable NiAl precipitates can be formed, and b) it is a useful model system with which to study the effects of interfacial and strain energy on coarsening processes. The modelling of the kinetic processes requires a detailed and accurate characterization of the precipitate morphology and composition. It is rare that a single technique is capable of completely characterizing a microstructure and in this study results from TEM and APFIM are presented. The Fe-Ni-Al-Mo materials reported in this investigation were Fe- 10 at.\%Ni- $15 \% \mathrm{Al}-1 \% \mathrm{Mo}$ and $\mathrm{Fe}-15 \% \mathrm{Ni}-20 \% \mathrm{Al}-4 \% \mathrm{Mo}$. These alloys formed part of the systematic study of Calderon et al $[1,2]$ and more details of the atom-probe analysis can be found in Miller and Hetherington [3]. All compositions are in atomic percent.

\section{RESULTS}

Two field-ion microscope (FIM) images of the $1 \%$ Mo alloy aged for $100 \mathrm{~h}$ at $775^{\circ} \mathrm{C}$ are shown in Fig. 1. No precipitates were observable in the images from these materials, even though the TEM micrographs shown in Fig. 2suggest that, after aging at $700^{\circ} \mathrm{C}$, there should be a high volume fraction of precipitates in the alloys (36\% [2]). Atom-probe experiments, however, revealed that many particles were present in the material, as shown in the composition profile in Fig. 3. Since they are invisible in the FIM, this indicates that a) their imaging characteristics are similar to the matrix and b) they are coherent with the matrix. It has been observed that Mo atoms image brightly in steels. Therefore, if Mo segregates to the matrix/precipitate interface, the interface might be expected to be decorated with brightly-imaging atoms. No such behaviour was observed.

The $4 \%$ Mo alloy aged for $50 \mathrm{~h}$ at $750^{\circ} \mathrm{C}$ did not show the same imaging characteristics. and two types of precipitate were observed. Though indistinct, a $\beta^{\prime}$ precipitate is shown in Fig. 4(a). The precise shape of the $\beta^{\prime}$ precipitate can seen more clearly while the specimen was field evaporating, as shown in Fig. 4(b). The precipitate shown appears to be ovoid, possibly from two coalescing spheres. Brightly-imaging FeMo precipitates were also observed in these alloys (Fig. $4 \mathrm{a}$ ) and one was analyzed as having a composition of $48.5 \% \mathrm{Mo}, 49.3 \% \mathrm{Fe}, 1.5 \%$ $\mathrm{Al}$ and $0.7 \% \mathrm{Ni}$.

The matrix composition measured by the atom probe is summarized in Table I and indicated that the matrix is depleted in nickel and aluminum. The matrix of the $1 \%$ Mo alloy was slightly enriched in molybdenum; whereas, the matrix of the $4 \%$ Mo alloy was depleted in molybdenum.

$\begin{array}{lllll}\text { Table I. } & \text { Average Composition of the } \alpha \text { Matrix } & \\ \text { Alloy } & \text { Mo } & \mathrm{Ni} & \mathrm{Al} & \mathrm{Fe} \\ 1 \% \text { Mo } & 1.2 \pm 0.1 & 2.2 \pm 0.2 & 11.8 \pm 0.4 & \text { Balance } \\ 4 \% \text { Mo } & 3.7 \pm 0.7 & 0.7 \pm 0.3 & 8.0 \pm 1.0 & \text { Balance }\end{array}$



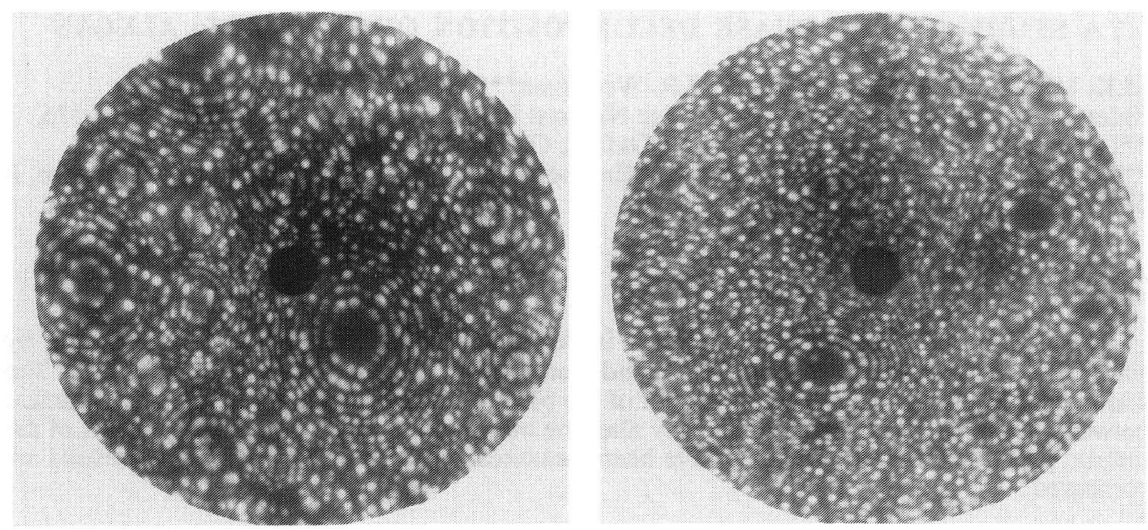
$775^{\circ} \mathrm{C}$

Fig. 1. Neon field-ion micrographs of $\mathrm{Fe}-10 \% \mathrm{Ni}-15 \% \mathrm{Al}-1 \%$ Mo alloy aged $100 \mathrm{~h}$ at
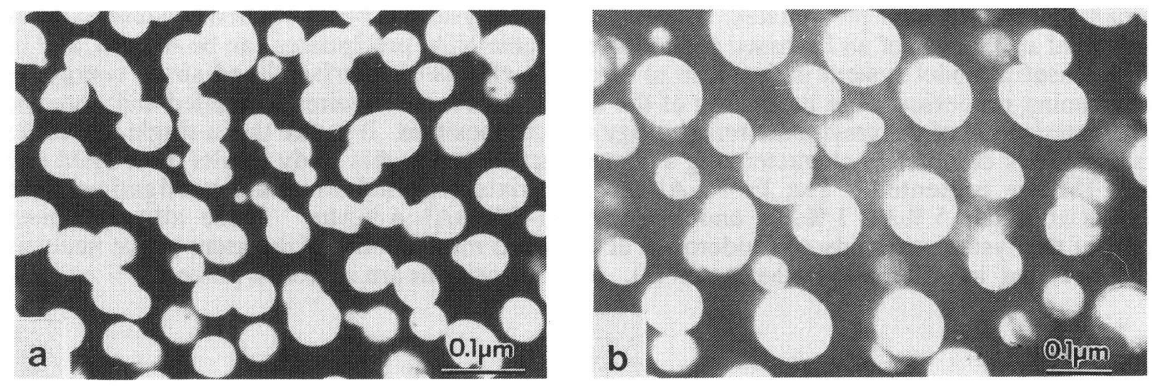

Fig. 2. NiAl particles in ferrite matrix after aging at $700^{\circ} \mathrm{C}$ for (a) $25 \mathrm{~h}$, (b) $100 \mathrm{~h}$

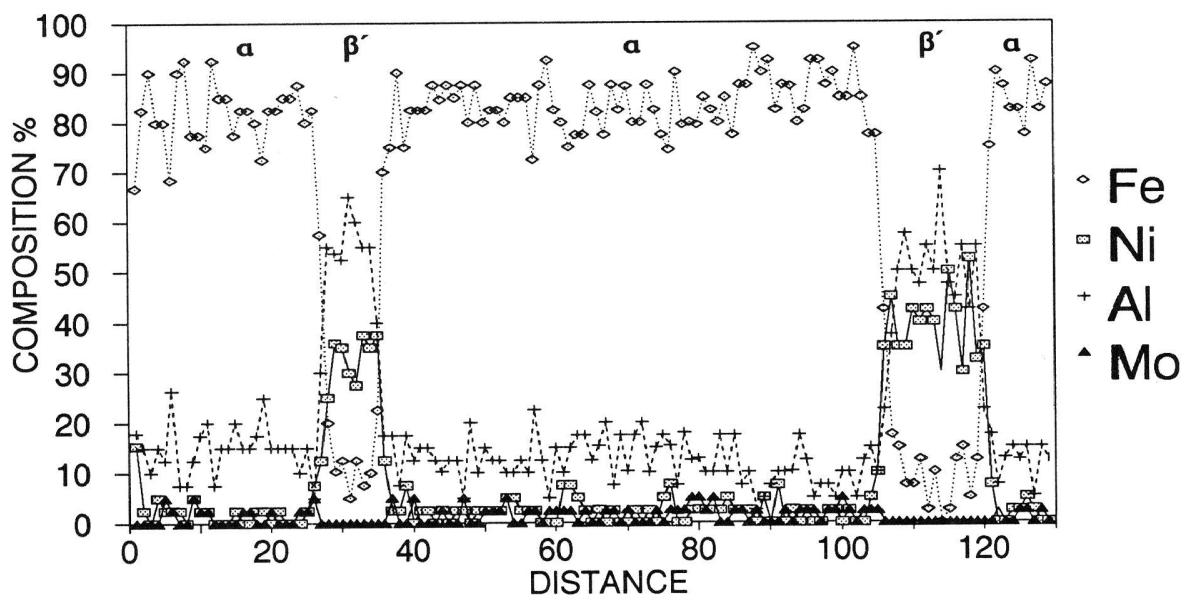

Fig. 3. Composition profile through $\mathrm{Fe}-10 \% \mathrm{Ni}-15 \% \mathrm{Al}-1 \%$ Mo alloy showing two $\mathrm{NiAl} \beta^{\prime}$ precipitates. The distance scale is in blocks of 50 ions. 

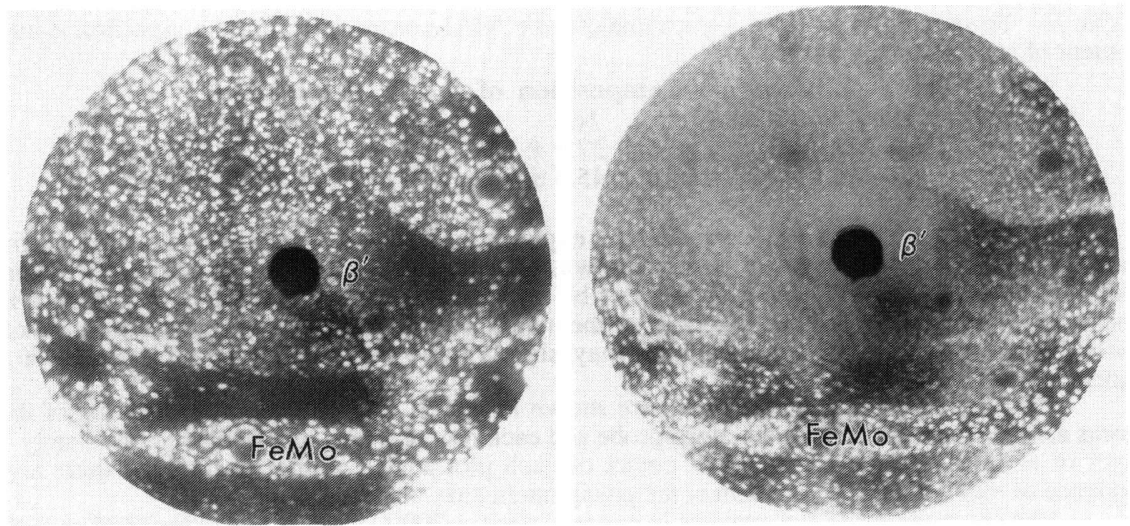

Fig. 4. Neon field-ion micrographs of Fe- $15 \% \mathrm{Ni}-20 \% \mathrm{Al}-4 \%$ Mo alloy aged $50 \mathrm{~h}$ at $700^{\circ} \mathrm{C}$. (a) at best image voltage and (b) during field evaporation.

\begin{abstract}
$++++++\mathrm{A}+\mathrm{A}+\mathrm{A}++\mathrm{A} \mathrm{A}+++\mathrm{A}+++++++++++++++$ $+\mathrm{A}+++++++++++\mathrm{A}++\mathrm{A}+++++\mathrm{A}++\mathrm{A}++++++++$ $+\mathrm{A}++\mathrm{A}+++++++++++++++++\mathrm{M}++++++\mathrm{A}++++$ $+++++\mathrm{A}++\mathrm{A}+++++++++\mathrm{AAA}++++.+\mathrm{M}+++++\mathrm{A}$ $++++++++++\mathrm{A}++.+.++. \mathrm{MM}+++++++++++++$ $++++\mathrm{A}++\mathrm{A}+\mathrm{A}+\mathrm{A}++\mathrm{AA}++++++\mathrm{A}+\mathrm{AAA}+\mathrm{A}+\ldots++$ $+++. A . . A+A \cdot A \cdot A++A \cdot A A A .+. A A A+. A+A A$ . AAAA+. . . AAAAAA. . AAAA....AAA+.+.AA A. . A. ++ . AAA. AAAA. A+. AAAA ++ . ..++. A AAAA. AA. . AAAAAAA. A. . AA ..+. AAA . . AA $A+A A . . . A A A A A A . A A A A . A A A A A . A A A .++. A$ $\mathrm{AAAA}+. \mathrm{AA}+\mathrm{AAA}+. \mathrm{AA} \ldots$. AAAAAAAAAA .... A. AAAA. AAAA . AAAA .. +AA.A+.AAA+ ..A A. . A.A. A. A. AAA+AAA. . AA+ .AA+A.A. + A. A. . AAA+. .AAA.A.A. A.A..+.AA. . A $. \mathrm{A}+\mathrm{A}+\mathrm{A} \cdot \mathrm{AAA} \cdot \mathrm{A}++. \mathrm{A} . .+\mathrm{A}+\mathrm{A}++\mathrm{A} \ldots \mathrm{A} .+.++$ $+\mathrm{A}+++++\mathrm{A}+++++++++++\mathrm{A}++++\mathrm{A}++\mathrm{A}+++.++$ $+++++++++\mathrm{AA}+++++\mathrm{A}++\mathrm{AA}+\mathrm{A}+++++\mathrm{M}+\mathrm{AM}++$ $++++\mathrm{A}+++++++++++++++++++++\mathrm{A}+++.+++$ $+++++\mathrm{A}+$
\end{abstract}

\section{Key}

$+=\mathrm{Fe} \quad \mathrm{A}=\mathrm{Al} .=\mathrm{Ni} \mathrm{M}=\mathrm{Mo}$

$\mathrm{P}=\mathrm{P} \quad \mathrm{s}=\mathrm{Si}$
$+++.+++++\mathrm{M}+++++++++\mathrm{A}+\mathrm{A}+++\mathrm{MMA}++++++$ $++++++\mathrm{A}+++++++\mathrm{A}++++\mathrm{A}++++++++++++++$ $+++\mathrm{AA}+++++++++++++++++++++++. \mathrm{A}+\mathrm{AM}+$ $+++\mathrm{A}++++++++++++++\mathrm{A}+++++++++++++++$ $+++++++++\mathrm{A}+\mathrm{A}+\mathrm{M}++\mathrm{A}+++++\mathrm{A}+++++++++++$ a $++++++++++\mathrm{A}+++\mathrm{A}+++++++\mathrm{MA}+++++\mathrm{A}++++$ $++++++.++.+\mathrm{A}+++++\mathrm{AA}+++++.++\mathrm{A}++++++$ $+\mathrm{A}++++$. . .+ . $+\mathrm{AA}+++++++\mathrm{M}++\mathrm{P}+\mathrm{AA}++\mathrm{A}+$.

$\rightarrow++\mathrm{A}++++.+\ldots \mathrm{A}++\mathrm{A} \ldots . . \mathrm{A}+. \mathrm{A} . \mathrm{A}+\ldots++\ldots$ A. AA. ...+. +A+A.A.A++A. A. . A. AAAA + . A. A. . AA.A. +. A+AA.+. AAAAAA. AA+. + + AAA + AAAA . . AA. . AAA+AAAAAA. A+A. . A.A. $+A A . A A A . A+. A A .+\ldots A \cdot A A . A A A \cdot A$ $\ldots A A \cdot A A A A \cdot A+\ldots A \cdot A A A+\ldots \ldots++. A+A A$ $A A A$. AAA. AAA. . AAA+.A.A.A.A. . AAA . A

$\beta^{\prime}$. AA.A.A.AAA...A.A+A.AAA. .AAA.A.AA. . AAAAA. AA. AA+A. AAAA.A. A . . A+A+. A.. AAAAAAA.A. AA ... AA. AAAAAAAAAAA . AAA . . AA . AAAA . AAA . AA. +A . ....A A...AAAA...A.AA..A.A+ ..A+AA.AA.A A. $+A A \cdot A A \cdot A A A . . . A A \cdot++. A A A \cdot A \cdot+A A A A A$ + . A . +AAA.A...A A A A.A. . A AA. +.A.A . A. .AAA . . AA+ . AA. . . A.AA.AAA... A. A. A+AA. A. AAA. AAAA.AA.A. +A+. AAAA $\rightarrow$ At.+.A..+A...+. +A+...+.A.A++A..+A $+\mathrm{A}++\mathrm{A}+.+++++\mathrm{A} A+\mathrm{AA}+\mathrm{A} .++++++++\mathrm{A}++\mathrm{A}+$. $+++++\mathrm{A}+.++++++\mathrm{A}+++++++++++++++\mathrm{A}+++$ $\mathrm{M}+++++\mathrm{A}+++++++++++\mathrm{A}+++++++++++++++$

a $++++\mathrm{A}++++\mathrm{A}++++++++++\mathrm{A}++\mathrm{A} \mathrm{A}+++++++++$ $++\mathrm{A}+++++++\mathrm{A}++++++++\mathrm{A}++\mathrm{A}++++.++++\mathrm{AA}$ $++++\mathrm{A}+++\mathrm{A}+++++++++\mathrm{A}++\mathrm{A}++++++++++++$ $++\mathrm{M}++\mathrm{A}++.+++\mathrm{A}++\mathrm{A}+.++\mathrm{A} \cdot \mathrm{A}++++++\mathrm{M}++++$ $+++++++++\mathrm{A}+++++\mathrm{As}+++++++++++++++$ $++++++\mathrm{A}++\mathrm{A}+++++++.+++++++++++\mathrm{A}++++$ $++++++\mathrm{A}++++\mathrm{AA}+++\mathrm{A}+++++\mathrm{AM}+++++++\mathrm{AA}$

Fig. 5. Character plots of the Fe- $10 \% \mathrm{Ni}-15 \% \mathrm{Al}-1 \%$ Mo alloy. No segregation of molybdenum to the precipitate matrix interface was evident. 
The results from a number of precipitates in the $1 \%$ and $4 \%$ Mo alloys are summarized in Table II. The precipitates have approximately the NiAl composition with a significant iron content of approximately $11 \%$.

$\begin{array}{clccc}\text { Table II. } & \text { Average Composition of the } \beta^{\prime} \text { Precipitates } \\ \text { Alloy } & \text { Mo } & \mathrm{Ni} & \mathrm{Al} & \mathrm{Fe} \\ 1 \% \text { Mo } & 0 & 37.9 \pm 1.6 & 50.9 \pm 1.7 & 11.3 \pm 1.0 \\ 4 \% \text { Mo } & 0.08 \pm 0.02 & 45.5 \pm 0.4 & 43.0 \pm 0.4 & 11.4 \pm 0.2\end{array}$

The existence of the FeMo precipitates explains the low molybdenum level of the matrix in the 4\% Mo alloy. This type of precipitate was not observed in the 1\% Mo alloy. However, there is a low level of Mo, and it is not possible to calculate a volume fraction of $\beta^{\prime}$ which is consistent with the observed compositions of the matrix and particles. This suggests that either a second type of precipitate may exist, or may simply arise because the precipitates have a distribution of compositions.

Two examples of character plots are shown in Fig. 5. The character plot is a list of the atoms as they were detected by the atom-probe and each row of atoms represents approximately 1 layer of atoms. The particle is at the centre of each plot and in neither example is there any evidence of molybdenum enrichment at the precipitate/matrix interface.

The composition of the particles in material aged at $700^{\circ} \mathrm{C}$ was estimated by TEM as $50 \%$ $\mathrm{Ni}, 30 \% \mathrm{Al}$ and $20 \%$ Mo from structure factor calculations. It was observed by $\mathrm{X}$-ray diffraction [2] that the molybdenum additions to these materials change the lattice misfit between the precipitates and the matrix. TEM indicated that molybdenum stabilized the spherical morphology of the precipitates. It was suggested that this stabilization was due to segregation of molybdenum to the precipitate-matrix interface changing the interfacial energy and surface stress and that this was consistent with changes in contrast at the edge of precipitate images.

\section{CONCLUSIONS}

Atom probe analyses have shown that molybdenum and iron partition preferentially to the $\alpha$ matrix and nickel and aluminum partition to the $\beta^{\prime}$ precipitates in an $\mathrm{Fe}-\mathrm{Ni}-\mathrm{Al}-\mathrm{Mo}$ alloy and that the $\beta^{\prime}$ precipitates have a significant iron content. No evidence was found for molybdenum segregation to the precipitate/matrix interface from either the FIM or atom-probe.

The atom probe results are not consistent with compositions of particles and interfaces estimated by TEM. There are three possible sources of this discrepancy. First, it is possible that the difference is due to the temperature difference in heat treatments of $75^{\circ} \mathrm{C}$ and the different aging times. Second, the inconsistency in the calculated volume fractions of the precipitates in the $1 \%$ alloy indicates that either a third phase is present or there is a systematic error in the atomprobe results. However, it is unlikely that, even if there were a systematic error, it would cause an apparent reversal in the direction of the segregation. Third, the interpretation of structure factor contrast is not always straightforward and it is possible that the proposed (TEM) compositions are not unique solutions for the observed contrast.

\section{ACKNOWLEDGMENTS}

The authors would like to thank K.F. Russell for her technical assistance. This research was sponsored by the Division of Materials Sciences, U.S. Department of Energy, under contract DE-AC05-84OR21400 with Martin Marietta Energy Systems, Inc. MGH gratefully acknowledges financial support from the SERC.

\section{REFERENCES}

1. H.A. Calderon, J.R. Weertman and M.E. Fine, Proc. 2nd International Conference on Solid-Solid Phase Transformations, Phase Transformation, 87, Cambridge, July 1987, ed. G.W. Lorimer, pub. Institute of Metals, England, 495 (1988).

2. H.A. Calderon, M.E. Fine and J.R. Weertman, Metall. Trans., 19A, 1131 (1988).

3. M.K. Miller and M.G. Hetherington, J. de Phys., $\underline{50-C 8}, 425,(1989)$. 